\title{
What's the Missing Link? - Reviewing Climate Change Polices in Context of Indian Agricultural Sector
}

\author{
Surabhi Mittal ${ }^{1} \&$ Srabashi Ray ${ }^{2}$ \\ 1 Senior Scientist- Agricultural Economist, Socioeconomics Program, International Maize and Wheat \\ Improvement Center (CIMMYT), India \\ 2 Research Associate, Socioeconomics Program, International Maize and Wheat Improvement Center \\ (CIMMYT), India \\ Correspondence: Surabhi Mittal, Socioeconomics Program, International Maize and Wheat Improvement Center \\ (CIMMYT), Building No. 7-B, 2nd Floor, Opposite Metro Pillar No 153, Rajendra Park, Pusa Road, New Delhi \\ -110060, India. Tel: 91-971-115-4443. E-mail: s.mittal@cgiar.org
}

Received: June 13, 2015 Accepted: July 21, 2015 Online Published: August 18, 2015

doi:10.5539/ass.v11n24p268 URL: http://dx.doi.org/10.5539/ass.v11n24p268

\begin{abstract}
Government of India has recently announced for special funds like National adaptation fund to handle market risks arising due to climatic variability. The operational protocol of this fund and other forthcoming initiatives have yet to be expanded, but through this paper we like to draw attention to some of the policies and programmes that the Governments of India have already initiated and that directly or indirectly link to managing the risks and challenges faced with climate change in context of agriculture sector. These policies have their own merits and demerits, but it is the need of the hour to draw synergies between the existing polices and new proposed actions to draw on the strengths of the ongoing programs and build up on that. This paper is also relevant in the context of UN Climate summit 2014 held on $23^{\text {rd }}$ September and Food and Agriculture Organisation (FAO) aim at a global alliance for climate smart agriculture along with India's prime ministers speech on $15^{\text {th }}$ august, 2015 and the budget speech emphasising on threat that agriculture is facing because of climate change and government willingness to give emphasis on this agenda in context of agricultural sector. With the critical analysis, we also want to highlight the richness in the policy framework of several policies which are interlinked with each other, but due to lack of coordination they implementation might not be very appropriate.
\end{abstract}

Keywords: agriculture, climate change, policies and programs, food security, India

\section{Introduction}

The issue of climate change has been emphasised in India's policy making over the last decade through several policies focusing on various aspects of climate change. This is evident from the ambitious launch of National Action Plan for Climate Change (NAPCC) which was adopted on $30^{\text {th }}$ June, 2008, the National Adaptation Fund (NAF) and an overall shift towards sustainable practices to achieve India's developmental goals (Government of India, 2008a)

India's climate change policy has been driven by principle of equity - "that must allow each inhabitant of the earth an equal entitlement to the global atmospheric resource" (Rai \& Victor, 2009). Over the last decade and a half India has adopted a more pro-active approach to climate change policy with the vision 'to create a prosperous, but not wasteful society, ... self-sustaining in terms of its ability to unleash the creative energies ... (and) mindful of (our) responsibilities to both present and future generations' (Government of India, 2008b). It is strongly influenced by the priorities of poverty eradication and enhanced socio-economic development. India's climate change policy strongly echoes the principles of the global alliance for Climate Smart Agriculture (CSA) led by the Food and Agriculture Organisation (FAO) (Food and Agriculture Organisation, 2014). The basic principle of CSA that India has adopted is to sustainably increase agricultural productivity and develop resilient food systems while reducing GHG emissions.

But, inspite of these initiatives, India remains the third highest green-house gas emitter (Olivier, Maenhout, \& Peters, 2012) after US and China. It is due to the lack of any consistent framework that guides India's effort towards reduction in emission ( Dubash, Raghunandan, Sant, \& Sreenivas, 2013). 
In this article we explore the climate change policies of India and identify the 'missing link' between several policies addressing similar objectives. This paper showcase national level policies of the Government of India (GOI) that outlines India strategy to deal with the issue of climate change. It focuses on the agricultural sector because of its vulnerability to climate shocks as well as significant contribution greenhouse gas (GHG) emissions. Simultaneously, it presents a critical analysis of these policies to highlight the scope for improvement in policy design as well as its implementation.

In this article we adopt a broader definition of climate change policy which includes policies that aim at mitigation of emissions as well and management of current market risk and production risk due to climate adversities. The discussion in the paper is divided into three sections- the first section talks about the status, goals and objective of the national policies on climate change with focus on agriculture sector. The second section present the missing link between these policies which is supplemented by the critique of these policies from the literature review. The conclusion is presented in the last section.

\section{Climate Change and Agriculture in India: Policy Framework}

Developing countries continue to be trapped in the 'intractability of poverty, social exclusion and inequality' (Kabeer, 2009) which are significant impediments for economic growth and inclusive development. Sustained and rapid agricultural growth has been argued to have the strongest impact on poverty alleviation (Dell, Jones, \& Olken, 2012; Irz, Lin, Thirtle, \& Wiggins, 2001). A large share of the population in developing countries is directly or indirectly linked with the agriculture sector. Hence, it is important to understand the factors that impact the growth and development in this sector. In recent times, the agricultural sector has become largely susceptible to the increasing incidence of climate shocks and variability leading to vulnerability in economic growth along with food scarcity and food inflation. According to one of the estimates by Guiteras (2009), yield of major crops in India can fall by 4.5 to 9 per cent due to climate change. More specifically, Auffhammer, Ramanathan \& Vincent $(2006,2012)$ attributes the stagnation of rice yields in the 2000s to climate change (Note 1). Results presented by Duncan, Dash \& Atkinson (2015) show that rising night temperatures in Punjab and Haryana is leading to fall in average wheat crop yield. Agriculture and climate change seems to be trapped in a vicious cycle. Notwithstanding the negative impact of climate change that agriculture bears, the sector also significantly contributes towards Green House Gas (GHG) emissions leading to climate change. According to the IPCC report (2014), agriculture and its allied sectors contributed to 20-25 per cent of global emissions in 2010. India is a significant contributor to methane emissions (IPCC, 2014) and hence it needs to actively and effectively undertake strategies for mitigation without compromising on countries priorities of food security and agricultural development. In this context India faces the complex challenge of balancing between climate change mitigation and inclusive economic growth. Presently the agriculture sector is largely driven by policies and technologies which are emission intensive (Garg, Bhattacharya, Shukla, \& Dadhwal, 2001; Pathak, Li, \& Wassmann, 2005). However, any changes in agricultural practices has to account for the intrinsic importance of the sector toward food security as well as the fact that it is the source of employment for almost half of India's population (Ministry of Statistics \& Programme Implementation, 2014).

Climate change is a long term phenomenon and to tackle the risk associated with it, government also formulate policies to safeguard farmers, poor producers and consumers in rural and urban locations. Some of these policies are targeted directly towards long term climate change linked mitigation strategies and enabling the population to adapt to the changes, others are also short term risk covers that help these vulnerable populations to cope with the risk that directly or indirectly are due to climate change and climatic variability. Most of the policies are usually not formulated keeping climate change directly in the frame, and thus these policies directly falls under the main objective of ensuring food security to all. Thus these policies are directed to either reduce production risk through improved production and productivity or they try to provide food at reduced prices that help poor to get food at affordable or subsidised prices even if the food inflation is high due to market uncertainties. The linkages between government policies on climate change with managing risk and ensuring food security is presented in the framework of policies as presented in Figure 1. Climatic variability through production and market uncertainties pose threat on food security situations. Thus different agricultural food policies are designed to tackle different aspects of these risks, but some do cover both the aspects too. Because farmers and poor consumers vary in their attitudes toward risk and their ability to address risk-prone situations, risk management cannot be viewed within a "one size fits all" approach.

Two primary policies designed by the Government of India for the purpose of food security and sustainability are the National Agricultural Policy (NAP) in 2000 and more recently, the National Mission for Sustainable Agriculture (NMSA) as one of the 8 missions under the National Action Plan for Climate Change (NAPCC) in 2008. The NAPCC is the over-arching policy document that envelops eight national missions. The underlying 
principles of the NAPCC, seek to mitigate climate induced risk and this embodies a 'directional change' in the approach to climate change in India. While adaptation has been the only focal point in the past, the NAPCC appreciates the importance of mitigation; given rapid economic growth, at the cost of enhanced climate vulnerability is an unsustainable path for development (Government of India, 2008b).
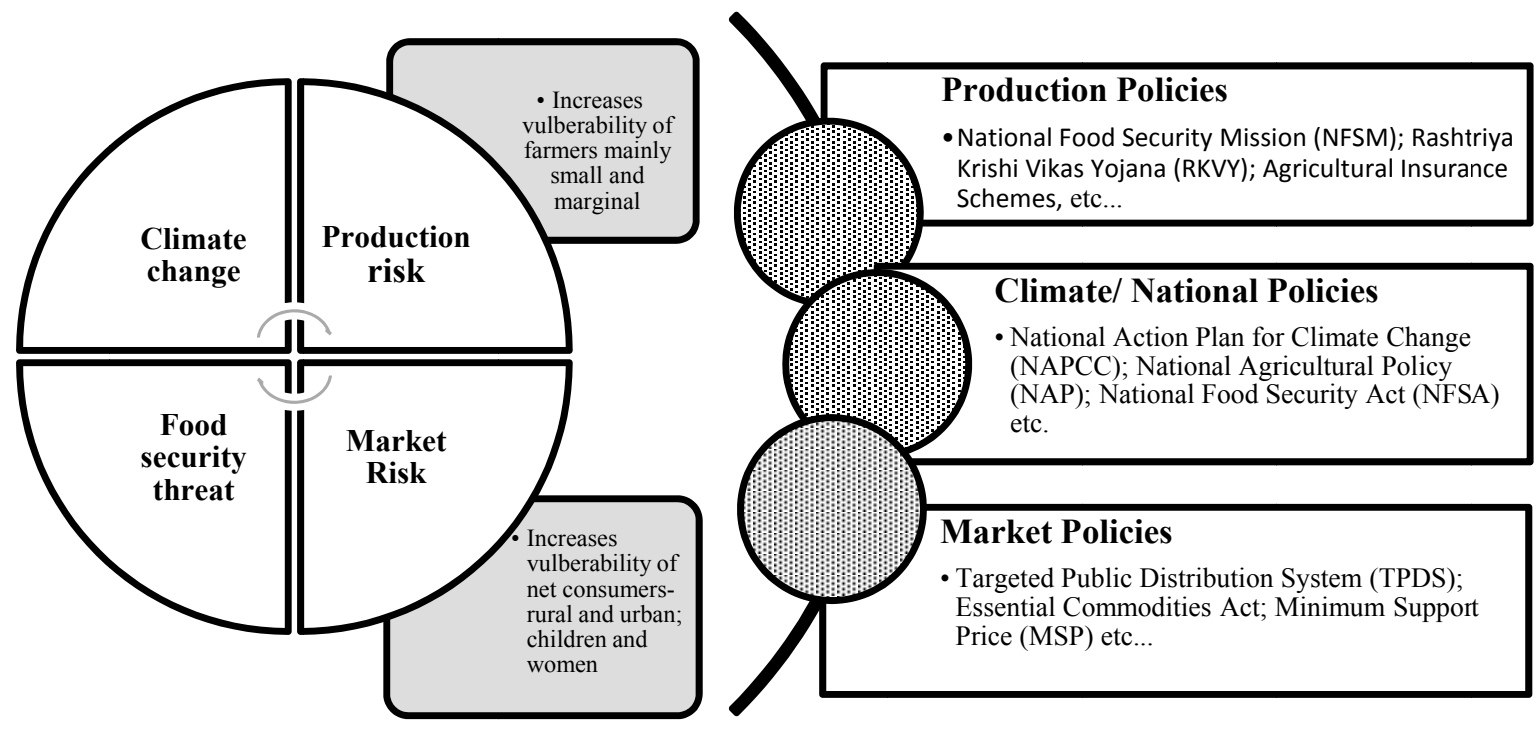

Figure 1. Framework of policies

In addition to the NMSA which directly influences agriculture, the NAPCC also comprises of the National Mission on Strategic Knowledge on Climate Change (NMSKCC). Under this Mission, the effort is to encourage research, innovation and extension of CSA practices. Along with the NMSA and NMSKCC, India has several other policies and programmes such as public distribution system, minimum support prices, subsidies on machineries that can be co-ordinated to develop a comprehensive short-terms risk mitigation system, along with long term strategy for emission reduction like use of climate smart technologies and conservation agriculture technologies.

\section{Present Policies Linked to Climate Change and Agriculture}

While reviewing climate change from a socio-economic point of view, climate change policy needs to be appreciated in association with welfare policies like The National Food Security Act (NFSA) that is challenged with providing subsidised food across poor households even in the incidence of severe climatic shocks. These policies mitigate the risks of climate shocks by safeguarding farmers against production and market risks such as ensured returns on production through minimum support prices, safety net against crop loss through various insurance schemes, ensuring availability of appropriate inputs etc. In addition, climate change policy also targets market risks from the perspective of poor and vulnerable consumers in rural and urban locations.

Guided by the NAPCC, the NMSA strives to modify Indian agriculture to be climate resilient while enhancing productivity in order to meet the food security challenge of India. This goal needs to be addressed in two steps: (i) adopting climate smart technologies; and (ii) managing production and market risks. One of the primary aims of the NMSA is technological innovation that prioritise socio-economic development with co-climate-benefits (Government of India, 2008b) to adapt or mitigate climate vulnerabilities of Indian agriculture (drought, flood, vagaries of precipitation). It is imperative to move away from chemical fertiliser and large irrigation-led agriculture to climate-smart practices of climate adaptation, resource conservation and enhanced productivity. In designing technological innovation, with a special focus on dry land agriculture, agricultural extension services and bio-technology it is important to ensure that it does not become exclusionary in nature as its target beneficiaries are a number of small and marginal farmers. The NAPCC advises the NMSA to combine traditional knowledge and practise systems with modern adaptation and mitigation effort. The National Mission on Strategic Knowledge for Climate Change (NMSKCC) has been designed to co-ordinate between the various sources of information to facilitate meaningful knowledge exchange (Government of India, 2010).

With somewhat similar objectives, The National Food Security Mission (NFSM), launched in 2007, initiated the 
process of adopting sustainable agricultural techniques like nutrient management, resource conservation, along with capacity building of farmers, specifically in rice, wheat and pulses. The implementation of the Mission is through existent institutions at the centre, states, district and village level. At the state level it co-ordinate with various State Agricultural Universities (SAUs), Indian Council of agricultural Research (ICAR) institutes, State Agricultural Management \& Extension Training Institute (SAMETI) and is guided by the State Food Security Mission Executive Committee (SFSMEC) which is constituted by the Mission. At the district level the primary implementing agency is Agricultural Technology Management Agency (ATMA) in close co-ordination with the KVKs, PRI system etc. (Government of India, 2007). The Rashtriya Krishi Vikas Yojana (RKVY) has been designed for integrated agricultural development and providing institutional support for technological innovation towards reduction in yield gap of various crops. The RKVY is federal in nature and has inbuilt flexibility to adopt 'focused interventions' depending upon the specific agro-climatic conditions. This focus has great relevance to customise the adoption of CSA as well as prioritising different practices on changing agro climatic dynamics with long term predictions in mind. For e.g. changing land use pattern for diversification towards crops that will be resilient to future climatic conditions. In Haryana, where depleting ground water level is of growing concern (Bhalla, 2007), government policies are encouraging diversification of rice towards maize (Government of Haryana, 2014).

There has been some effort to design NMSA as one comprehensive policy by merging it with other programs which also target sustainable agriculture. The Annual Plan document, 2013-14, of the Ministry of Agriculture subsumes Micro Irrigation (MI), National Project on Management of Soil Health and Fertility (NPMSHF), Rainfed Area Development Programme (RADP) and Macro Management of Agriculture (Soil \& Water conservation and Land Reclamation Programmes) into the NMSA and treat each of these as sub-missions. In addition to adaptation to climate change ex-ante, the NMSA is also responsible for mitigating risks, ex-post. For instance the several welfare policies such as the Minimum Support Price (MSP), National Food Security Act (NFSA) which encompass ICDS, MDM, TPDS and other food security related schemes along with agricultural insurance schemes such as Weather Based Crop Insurance Scheme (WBCIS), Comprehensive Crop Insurance Scheme (CCIS), Farm Income Insurance Scheme (FIIS) and Modified National Agricultural Insurance Scheme (MNAIS) are important safety-nets in case of a crop failure. These schemes have been designed as safety nets for producers and consumers of agricultural produce in times of stress.

In addition to the NMSA, India also has the National Agricultural Policy (NAP) and National Food Security Mission since 2000. The NAP is the guiding document for contemporary Indian agriculture, with the long term goal of achieving and sustaining 4 per cent annual agricultural growth. It is driven towards the achievemnent of self reliance in food production, contribute to household food security and narrow the level of inequality in the economy. NAP was designed to tap on this hidden growth potential by strengthening rural infrastructure, reduction in price volatitlity, encouragement of private and group participation, focus on non-agricultural activities in the primary sector, greater value addition, growth of small scale agro-businesses and generation of gainful employment within the sector (Singh, 2002). This aim of self reliance is threatened due to climatic variability. Exposure of important cereal crop such a wheat or rice to untimely precipitation and excess can cause to widespread crop failure and scarcity of food.

Under the global alliance for CSA, knowledge trnsfer plays a significant role. An 'inclusive, knowledge sharing platform' is central to the approach suggested by the FAO (Food and Agriculture Organisation, 2014). To create awareness and increased adoption of climate smart agriculture practices, National Mission on Strategic Knowledge for Climate Change (NMSKCC) adopted in July 2010 complements the NMSA policy. NMSKCC feeds into the knowledge base that caters to both production and market risk management policies. The Mission document is drawn in light of the fact that various sources of information co-exist but these are varied, in terms of size, nature of institutions and information, and dispersed across the length and breadth of the country. The NMSKCC proposes a co-ordinated mechanism and process with a view to further enhance the effectiveness and impact of various existing intra- and extra-mural knowledge generating systems in the country' (Government of India, 2010).

Two sub-missions have been adopted by NMSKCC: (i) one pertains to knowledge management regarding the different aspects of climate shocks such as floods, droughts etc. and (ii) the other deals with key sectors that are affected by climate shocks such as agriculture, health etc. The NMSKCC states the importance of research suited to local climate conditions and indigenous knowledge systems. At the same time build alliances and partnerships through global collaborations, to develop national capacity for research, infrastructure, human resources etc. This mission should work closely with the National Agricultural Research System (NARS) in India. The system was established in 1905 and spearheaded by the Department of Agricultural Research and Extension (DARE). It 
focuses on agricultural research and education in India. It also manages several programs towards the goal of knowledge generation and dissemination in the agricultural sector.

NMSKCC also needs to closely link with The National Agricultural Innovation Project (NAIP) and Agricultural Technology Management Agency (ATMA), two contemporary knowledge generation and dissemination programs for improving accumulation and dissemination of technology and knowledge. The NAIP, funded by World Bank, is designed as one of the tools to achieve the 4 per cent agricultural growth target undertaken by the NAP. It specifically targets the objectives of generation and transfer of agricultural technologies and reform the current system (ICAR, 2012). The Project recognises the constraints that small size of land holdings has limited the use of technology, initial adverse impacts of climate change, pertaining to soil erosion, unpredictable precipitation, and deterioration in soil quality have set in etc. In this background, the NAIP adopts a positive approach to integrate the market in sorting out some of the bottlenecks and recognises the untapped potential which can be released with the help of technological advancement. The overall objective is to achieve accelerated and sustainable transformation within the agricultural sector which will directly impact poverty alleviation and livelihood generation. NAIP has two set of priorities. Firstly, institutional development which aims for a delicate balance between utilization of indigenous knowledge and creation of new knowledge while maintaining documentation, validation and dissemination of knowledge. Secondly, Research \& Development $(\mathrm{R} \& \mathrm{D})$ priorities of NAIP are dynamic in nature as they are developed according to local requirements. Agricultural diversification, livestock \& fisheries production, genetic resource and bio-prospecting, natural resource management, integrated pest management, value addition and post harvesting processes are a part of it. This is complemented with Agricultural Technology Management Agency (ATMA) project launched in 1998. This responsibility of the ATMA, in each districts, is to integrate extension programs across key line departments; link research and extension activities within each district; and decentralize extension decision-making through a participatory program planning process that would directly involve all categories of farmers, including farm women, in setting extension priorities and assessing programs at the block and district levels. Both ATMA and NAIP are expected to aim at transfer of technology using modern means of communication (Mittal and Mehar, 2012). They aim at transferring information and knowledge about CSA practices that enables farmers to reduce risk, impact of climate shocks and also enable them to mitigate and adapt to the impact of climate change. By this these two programs contribute to the mission objectives of NMSKCC.

\section{Identifying the Missing Links and Moving Forward}

\subsection{Lack of Clarity}

While the NAPCC clearly illustrates the principles of climate change policy for India, specific goals, targets and prioritisation of the same is missing. It shies away from committing quantitatively to reduction of emissions or energy efficiency notwithstanding some existent targets in other government documents (Agarwala, 2008; Byravan \& Rajan, 2012; Sanwal, 2008). The only quantitative target is to continue its status quo of not exceeding per capita emissions of developed countries. The Plan needs to be revised with the aim of greater clarity in actions and short to medium terms goals. Rai and Victor (2009) argue that on one hand it contains cost effective and ready to be implemented policies, while on the other it appears to be a wish list of policies that are difficult to be achieved in the short or medium term. There is a lack of coordination across the various missions of the Plan. The policy review presented by IFMR (2012) points out that some of the missions are confusing and lacks clear direction.

\subsection{Business as Usual}

NAPCC is often critiqued as a 'business as usual document' which does not significantly change the status quo similar to the NMSA which also forms the backbone of India's approach to climate sensitize agricultural practices and have limited suggestions for strategic changes (Byravan \& Rajan, 2012; Ramanjaneyulu \& Kuruganti, 2009). The Mission fails to translate the urgency of the climate change problem and it's inter linkages with agricultural practices and further into policy. E.g. over dependence on chemical fertilizers continues to persist. Further, research and innovation towards shock resistant crop varieties, particularly in case flood and drought, has not been stressed. The kind of innovation that is included in the mission is critiqued to be 'narrow' and 'market-driven' with excessive focus on technological innovation that might be skewed toward large farmers. Suggestions of Ramanjaneyulu and Kuruganti (2009) argue that the approach continues to be of a top-down 'lab to land' nature which primarily required over dependence of farmers on agricultural extension services from the government. The nature of agricultural extension services are very poor, infrastructural bottlenecks traps farmers at a sub-optimal equilibrium, inefficient incentives and lack of appropriate safety nets stifles scalable innovation (Byravan \& Rajan, 2012). Thus, to fulfil the objectives outlined by the NMSKCC, it is imperative for the 
Mission to identify the different initiatives that are currently being undertaken by various stakeholders in the country and identify the potential players from the current pool of experienced institutions. Understanding of the target groups and how it impacts them can also help in strengthening the impact of information (Mittal \& Mehar, 2015). No attempt has been made to capture the rich and unutilised pool of indegenous knowledge amongst the farming community itself, which are crucial for scalbility of these policies.

\subsection{Missing Coordination}

A major gap in the NAPCC mission is its lack of emphasis on management of marketing risks which insures the consumers as well as the producer in the eventuality of climate shocks. In addition the failure of rest of the institutional framework, regulation and financial, has not been adressed in the Mission. There is a lack of co-ordinating the NMSA with other flagship programmes such as the NAP, NFSA, RKVY, NFSM etc. For instance, funds under the RKVY scheme can be used to finance programs/projects directed towards the goals of NMSA. Similarly the NAP and the NFSM has overlapping targeting which can be merged together to avoid duplication of ineffective policies. The NMSA suggests the adoption of technology driven strategies. However, it fails to appreciate the context in which these schemes are to be designed and implemented. One repetative critique of the NMSA is that it has not been a consultative process between the policy makers and the farmers (Byravan \& Rajan, 2012; Ramanjaneyulu \& Kuruganti, 2009). Across the nation there is an existant chain of government sponsored argicultural universities and extension systems. This pool of resources shall be channelised into research and innovation for climate sensitive agriculture in close consultation with the agirucltural community. However, it's ironical to note that NMSKCC falls significantly short of providing a detailed typological list of the various initiatives and its linkages with the other seven sub-missions of the NAPCC is week (Byravan \& Rajan, 2012). The objective of the mission that aims to fine tune research and its dissemination to the local needs of each region is designed in a centralised fashion rather than a participatory method, and thus it misses out on tapping local knowledge and appreciating the various gaps that exist in the field.

\subsection{Creating Impact}

Although ATMA project is a significant move in the direction of participatory approach for agricultural research and extension, it is important to link it up with the NMSKCC so that it is not resource constrained either financially or with adequate capacity and skilled personnel, which actually was a big constrained in the phase of scaling up of ATMA (Feder, Anderson, Birner, \& Deininger, 2011; Singh \& Meena, 2011). The Agricultural Finance Corporation (AFC) in 2009-10 reported that 52 per cent of respondent farmers said that they gained knowledge of new practices and technologies. However, only 25 per cent felt that this had helped to increase production (Government of India, 2013). Given this context it is mandatory to undertake large scale human resource development in order to bring about thorough change in attitude.

The implementation framework of ATMA needs to be dynamic and modernised. The long standing approach of treating farmers as beneficiaries of doles shall be revamped into a business-like approach where the farmers are the end customers. Lenin, Singh, \& Vijayaraghavan, (2009), presents the findings of a study conducted in Ahmednagar and Dahod districts of Maharashtra and Gujarat respectively. It reports that a majority of the farmers did not monitor or assess the progress of on-field activities, did not have the power to veto or suggest any activity. However, another study reported that farmer participation is quite high in some districts of Kerala (Lenin, Singh, \& Vijayaraghavan, 2009). These studies report information of specific pockets and are unreliable to evaluate the study as a whole. It is important to undertake a pan-India evaluation study and identify localized problems that leads to differential performance of the ATMA and also feed it back in the system to strengthen the program.

\section{Conclusion}

Policies formulated act as the direction for future pathway towards development and thus in case of mitigating the climate risk, present policies act as the road map. Although at field and household levels farmers adopt different strategies that help them mitigate the risk against climate (Mehar, 2014), it is important to see how the government have taken initiative on these fronts. In order to understand this, the review of government policies presented in this paper is linked to climate change and food security that tends to either help in mitigating or adopting to production and market risk. The national action plan for climate change (NAPCC) has brought about a directional change in India towards the issue of climate change. It focuses both on adoption and mitigation and aims towards inclusive development keeping climate change effects and impacts in view. This plan has several mission but the issue is lack of coordination between the missions and actionable points are not very clearly laid out. National mission for sustainable agriculture (NMSA) and National mission on strategic knowledge for 
climate change (NMSKCC) are the two most important missions of NAPCC that have direct linkages with policies related to agriculture and climate change. NMSA puts priority on policies that promote use of technologies suitable for small and marginal farmers as well along with keeping in view the climate smart technologies need. This is in line with the CSA initiative undertaken globally by FAO which advocated voluntary adoption of national strategies directed towards CSA. NMSA looks into reducing production risk along with tacking market risk too through the government polices of MSP and crop insurance. NMSKCC works on establishing knowledge networks and develop data sharing platforms to tackle climate risk, but the linkages between NMSKCC and NMSA seems to be very week although both mission together can have netter focus and targeted approach. Also not much effort is made to capture the indegenous knowledge of farming community itself.

Most of the government policies are driven by the objective of food security and thus are more focused on improving productivity and reducing production risk. National agriculture policy aimed at achieving and sustain 4 per cent annual agricultural growth and laid emphasis on risk management schemes like crop insurance. NAP adopts agricultural policies based in agro-climatic conditions and thus try to incorporate the technologies that are suitable by climatic situations. But still the NAP base most of its policies on input and output subsidies and are carelessly combined with climate polices. The National food security act and other such policies are about distribution of subsidised food that help poor and others with low purchasing power to meet their food requirements and cover the market risk. But such policies without complementary support to sustainable and cost effective production system will be not a viable long term policy. Government of India also have various policies that aim at improving production and productivity. Some of these polices acknowledge that climate change and variability is the principal cause of production uncertainties and thus adoption of technologies that are climate smart can help in reducing climate and production linked risks.

\section{Acknowledgments}

This paper is drawn from the ongoing work that the authors are doing funded under the Climate Change, Agriculture and food Security (CCAFS) Project and is also supported by CRP Wheat.

\section{References}

Agarwala, R. (2008). Towards a Global Compact for Managing Climate Change. Discussion Paper 2008-22, Cambridge, Mass.: Harvard Project on International Climate Agreements, December 2008. Retrieved from http://citeseerx.ist.psu.edu/viewdoc/download?doi=10.1.1.177.6441\&rep=rep1\&type=pdf

Auffhammer, M., Ramanathan, V., \& Vincent, J. R. (2006). Integrated model shows that atmospheric brown clouds and greenhouse gases have reduced rice harvests in India. Proceedings of the National Academy of Sciences of the United States of America, 103(52), 19668-72. http://dx.doi.org/10.1073/pnas.0609584104

Auffhammer, M., Ramanathan, V., \& Vincent, J. R. (2012). Climate change, the monsoon, and rice yield in India. Climatic Change, 111(2), 411-424. http://dx.doi.org/10.1007/s10584-011-0208-4

Bhalla, P. (2007). Impact of Declining Groundwater Levels on Acreage Allocation in Haryana. Economic and Political Weekly, 42(26), 2701-2707.

Byravan, S., \& Rajan, S. C. (2012). An Evaluation of India's National Action Plan on Climate Change. SSRN Electronic Journal. Chennai. http://dx.doi.org/10.2139/ssrn.2195819

Dell, M., Jones, B., \& Olken, B. (2012). Temperature Shocks and Economic Growth: Evidence from the Last Half Century. American Economic Journal: Macroeconomics, 4(3), 66-95. http://dx.doi.org/10.1257/mac.4.3.66

Dubash, N. K., Raghunandan, D., Sant, G., \& Sreenivas, A. (2013). Indian Climate Change Policy. Exploring a Co-Benefits Based Approach. Economic and Political Weekly, XLVIII(22). Special article.

Duncan, J. M. A., Dash, J., \& Atkinson, P. M. (2015). Elucidating the impact of temperature variability and extremes on cereal croplands through remote sensing. Global Change Biology, 21(4), 1541-1551. http://dx.doi.org/10.1111/gcb.12660

Feder, G., Anderson, J. R., Birner, R., \& Deininger, K. (2011). Promises and realities of community-based extension. In K. Otsuka, \& K. Kalirajan (Eds.), Community, Market, and State in Development, a Festschrift in Honour of Professor Y. Hayami, Palgrave Macmillan, Basingstoke (pp. 187-208).

Food and Agriculture Organisation. (2014). Global Alliance for Climate-Smart Agriculture: Framework Document. Retrieved from http://www.fao.org/climate-smart-agriculture/41760Retrievedb1b86fcb1e 55efe8fa93ffdc5.pdf 
Garg, A., Bhattacharya, S., Shukla, P., \& Dadhwal, V. (2001). Regional and sectoral assessment of greenhouse gas emissions in India. Atmospheric Environment, 35(15), 2679-2695. http://dx.doi.org/10.1016/S13522310(00)00414-3

Government of Haryana. (2014). Haryana State Agriculture Policy. Retrieved from http://agriharyana.nic.in/Agriculture\%20Policy/English\%20Haryana_State_Agriculture_Policy_Draft.pdf

Government of India. (2007). National Food Security Mission. New Delhi. Retrieved from http://nfsm.gov.in/

Government of India. (2008a). Eleventh Five Year Plan (Volume III). New Delhi. Retrieved from http://planningcommission.nic.in/plans/planrel/fiveyr/11th/11_v3/11th_vol3.pdf

Government of India. (2008b). National Action Plan on Climate Change. New Delhi: Government of India. Retrieved from http://www.c2es.org/international/key-country-policies/india/climate-plan-summary

Government of India. (2010). National Action Plan on Climate Change Mission. Retrieved from http://www. nicra-icar.in/nicrarevised/images/Mission\%20Documents/National-Action-Plan-on-Climate-Change.pdf

Government of India. (2013). Twelfth Five Year Plan (2012-2017) Volume II New Delhi. Retrieved from http://planningcommission.gov.in/plans/planrel/12thplan/pdf/12fyp_vol2.pdf

Guiteras, Raymond (2009). The Impact of Climate Change on Indian Agriculture. mimeo, MIT Department of Economics, 2009. Retrieved from http://www.researchgate.net/profile/Robert_Mendelsohn/publication/ 5078253_Measuring_the_Impact_of_CLimate_Change_on_Indian_Agriculture/links/53da61ed0cf2a19eee8 $84 \mathrm{~d} 2 \mathrm{f} . \mathrm{pdf}$

IFMR. (2012). An Evaluation of India's Nation Plan on Climate Change. Mimeo. Retrieved from http://mitigationpartnership.net/sites/default/files/napcc_evaluation.pdf

Indian Council of Agricultural Research (ICAR). (2012). NAIP: Annual report 2011-12. New Delhi. Retrieved from http://www.icar.org.in/files/reports/icar-dare-annual-reports/2011-12/NAIP-AR-2011-12.pdf

IPCC, 2014: Climate Change 2014: Mitigation of Climate Change. Contribution of Working Group III to the Fifth Assessment Report of the Intergovernmental Panel on Climate Change [Edenhofer, O., R. Pichs-Madruga, Y. Sokona, E. Farahani, S. Kadner, K. Seyboth, A. Adler, I. Baum, S. Brunner, P. Eickemeier, B. Kriemann, J. Savolainen, S. Schlömer, C. von Stechow, T. Zwickel and J.C. Minx (eds.)]. Cambridge University Press, Cambridge, United Kingdom and New York, NY, USA. Retrieved from https://www.ipcc.ch/pdf/assessment-report/ar5/wg3/ipcc_wg3_ar5_full.pdf

Irz, X., Lin, L., Thirtle, C., \& Wiggins, S. (2001). Agricultural Productivity Growth and Poverty Alleviation. Development Policy Review, 19(4), 449-466. http://dx.doi.org/10.1111/1467-7679.00144

Kabeer, N. (2009). Social Protection in South Asia: A Review Social Protection in South Asia. Institute of Development Studies. August 2009. Retrieved from https://www.ids.ac.uk/files/dmfile/SocialProtection inSouthAsia.pdf

Lenin, V., Singh, B., \& Vijayaragavan, K. (2009). Decision making by the farmers in Agricultural Technology Management Agency. Pusa Agriscience, 32, 79-82.

Mehar, M. (2014). Gender specific impacts of climate variation in agriculture (Unpublished M.Phil. Thesis). Department of Economics, School of Social Science, Indira Gandhi National Open University, India

Ministry of Statistics \& Programme Implementation. (2014). Employment and Unemployment Situation in India. NSS $68^{\text {th }}$ round 2011-12. New Delhi. Retrieved from http://mospi.nic.in/Mospi_New/upload/nss_report_ 554_31jan14.pdf

Olivier, J. G. J., Maenhout, G. J., \& Peters, J. A. H. . (2012). Trends in global CO2 emissions; 2012 Report. PBL Netherlands Environmental Assessment Agency. The Hague/Bilthoven, 2012 PBL publication number: 500114022. http://dx.doi.org/10.2788/33777.

Pathak, H., Li, C., \& Wassmann, R. (2005). Greenhouse gas emissions from Indian rice fields: calibration and upscaling using the DNDC model. Biogeosciences, 2(2), 113-123. http://dx.doi.org/10.5194/bg-2-113-2005

Rai, V., \& Victor, D. G. (2009). Climate Change and the Energy Challenge: A Pragmatic Approach for India. Economic \& Political Weekly, xliv(31), 78-85. Retrieved from https://casi.sas.upenn.edu/sites/casi.sas. upenn.edu/files/uploads/Climate \%2BChange\%2B\%2526\%2Bthe\%2BEnergy\%2BChallenge $\% 2 \mathrm{~B}-\% 2 \mathrm{BVR}$, \%2BDV.pdf

Ramanjaneyulu, G. V., \& Kuruganti, K. (2009). Sustaining Agriculture in the era of Climate Change in 
India-Civil Society position paper. Center for Sustainable Agriculture Secunderabad - 500017, Oxfam India. Retrieved from http://indiaforsafefood.in/PDF/civil_society_position_paper_with_coverpage.pdf

Sanwal, M. (2008). To The G-8 and India 's National Action Plan on Climate Change. Economic and Political Weekly, 43(29), 17-18.

Singh, K. M., \& Meena, M. S. (2011). Agricultural Innovations in India-Experiences of ATMA Model (November 9, 2011). http://dx.doi.org/10.2139/ssrn.1989823

Singh, P. (2002). Agricultural Policy-Vision 2020. Planning Commission. Retrieved from http://planningcommission.nic.in/reports/genrep/bkpap2020/24_bg2020.pdf

Surabhi, M., \& Mehar, M. (2012), How Mobile Phones Contribute to Growth of Small Farmers? - Evidence from India. 2012. Quarterly Journal of International Agriculture, 51(3), 227-244. DLG-Verlag Frankfurt/M.

Surabhi, M., \& Mehar, M. (2015). Socio-economic Factors Affecting Adoption of Modern Information and Communication Technology by Farmers in India: Analysis Using Multivariate Probit Model. The Journal of Agricultural Education and Extension. http://dx.doi.org/10.1080/1389224X.2014.997255

\section{Note}

Note 1. Particularly, to atmospheric brown clouds (ABCs) which refers to air pollution emissions from burning of fossil fuel and biomass and greenhouse gas (GHGs) emissions

\section{Copyrights}

Copyright for this article is retained by the author(s), with first publication rights granted to the journal.

This is an open-access article distributed under the terms and conditions of the Creative Commons Attribution license (http://creativecommons.org/licenses/by/3.0/). 